JKAU: Comp. IT., Vol. 1 No. 2, pp: 45-67 (2012 A.D. / 1434 A.H.)

DOI: 7193 / Comp. 1-2.3

\title{
Using Variable-Entered Karnaugh Maps in Determining Dependent and Independent Sets of Boolean Functions
}

\author{
Ali Muhammad Ali Rushdi and Hussain Mobarak Albarakati \\ Department of Electrical and Computer Engineering, \\ King Abdulaziz University, Jeddah, Saudi Arabia \\ arushdi@kau.edu.sa
}

\begin{abstract}
An important class for Boolean reasoning problems involves interdependence among the members of a set $T$ of Boolean functions. Two notable problems among this class are (a) to establish whether a given subset of $T$ is dependent, and (b) to produce economical representations for the complementary families of all dependent subsets and independent subsets of $T$. This paper solves these two problems via a powerful manual pictorial tool, namely, the variableentered Karnaugh map (VEKM). The VEKM is utilized in executing a Label-and-Eliminate procedure for producing certain prime implicants or consequents used in tackling the two aforementioned problems. The VEKM procedure is a time-saving short cut indeed, since it efficiently handles the three basic tasks demanded by the solution procedure, which are: (a) To combine several Boolean relations into a single one, (b) to compute conjunctive eliminants of a Boolean function, and (c) to derive the complete sum (CS) of a Boolean function. The VEKM procedure significantly reduces the complexities of these tasks by introducing useful shortcuts and allowing simultaneous processing. The VEKM procedure is described in detail, and then demonstrated via two illustrative examples, which previously had only black-box computer solutions as they were thought to be not amenable to manual solution. The first example deals with switching or bivalent functions while the second handles 'big' Boolean functions. Both examples indicate that the VEKM procedure proposed herein enjoys the merits of insightfulness, simplicity and efficiency.
\end{abstract}

Keywords: Maximal independent subsets, Minimal dependent subsets, Boolean functions, variable-entered Karnaugh maps. 


\section{Introduction}

The dependence of collections of sets, propositions, or Boolean functions has many diverse applications ranging from the design of switching (Boolean) circuits $^{[1-3]}$ and the decomposition of switching (Boolean) circuits $^{[4]}$ to the solution of certain problems in enzyme biochemistry ${ }^{[5]}$ or medical diagnosis ${ }^{[6]}$.

In a seminal and highly-cited treatise on Boolean reasoning, Brown $^{[3]}$ considered two problems concerning a set $T$ of $m$ Boolean functions. The first is to establish whether a given subset of $T$ is dependent. The second is to produce an economical representation for the family of all dependent subsets of $T$ and the complementary family of all independent subsets of $T$. The Boolean functions considered are generally 'big' Boolean functions that are not necessarily restricted to the two-element, bivalent, or switching case. Brown ${ }^{[3]}$ presented a Labeland-Eliminate procedure for deriving all the relations, if any, holding among several functions. This procedure involves the three tasks of: (a) Combining several Boolean relations into a single one, (b) computing conjunctive eliminants ${ }^{[3,7]}$ or meet derivatives ${ }^{[8]}$ of a Boolean function, and (c) computing the complete sum (CS) or Blake canonical Form (BCF) of a Boolean function. Each of these three tasks is time consuming. Therefore, Brown ${ }^{[3]}$ did not illustrate the details of his procedure via manual examples, but was content to produce the final output of two examples via a computer program. One of his examples deals with switching (bivalent) functions, while the other handles 'big' Boolean functions.

This paper handles various dependency issues among Boolean functions, including the aforementioned two problems of Brown ${ }^{[3]}$, via a powerful manual pictorial tool, namely, the variable-entered Karnaugh map (VEKM) ${ }^{[7,9-18]}$. The VEKM is utilized in executing the Label-andEliminate procedure of Brown ${ }^{[3]}$. The VEKM procedure is a time-saving short cut, indeed, since it efficiently handles the aforementioned three tasks demanded by the Label-and-Eliminate procedure. The VEKM procedure proposed herein is a useful pedagogical tool that enjoys the merits of insightfulness, simplicity, and efficiency. In fact, the procedure is so efficient that it is capable of a fast solution of the earlier two examples in Brown ${ }^{[3]}$, which were believed to be extremely hard or even impossible for manual solution. 
The rest of this paper is organized as follows: Section 2 describes the Label-and-Eliminate procedure due to Brown ${ }^{[3]}$, while section 3 significantly simplifies this procedure, adapts it to VEKM implementation, and significantly reduces the complexities of the pertinent tasks required by introducing useful shortcuts to these tasks, and allowing the processing of two of them to run simultaneously. Section 4 demonstrates the VEKM procedure via the two classical examples of Brown ${ }^{[3]}$. The VEKM procedure efficiently and elegantly recovers the earlier computer solution of these two examples. The original Label-and-Eliminate procedure was too complicated for these two examples to allow manual solution. Section 5 concludes the paper. To make the paper self contained, it is supplemented with two appendices. Appendix A is a brief tutorial on the basic definitions and theorems on dependent and independent sets of Boolean functions, while Appendix B reviews basic notions and concepts of the variable-entered Karnaugh map.

\section{The Label-and-Elimination Procedure}

In this section, we briefly outline the Label-and-Eliminate procedure of Brown ${ }^{[3]}$. We look for relations among a collection of Boolean functions:

$$
f_{\mathrm{i}}(\boldsymbol{X}): \boldsymbol{B}^{\mathrm{n}} \rightarrow \boldsymbol{B}, \quad 1 \leq i \leq m,
$$

where $\boldsymbol{X}$ stands for an argument vector $\left(X_{1}, X_{2}, \ldots, X_{\mathrm{n}}\right)$. The system

$$
A_{\mathrm{i}}=f_{\mathrm{i}}(\boldsymbol{X}), \quad 1 \leq i \leq m,
$$

associates the symbols in the vector $\boldsymbol{A}=\left(A_{1}, A_{2}, \ldots, A_{\mathrm{m}}\right)$ with the corresponding functions. Brown ${ }^{[3]}$ introduced the following 3-step Labeland-Eliminate Procedure:

Step 1: Reduce (1) to the single equivalent equation

$$
\mathrm{g}(\boldsymbol{A}, \boldsymbol{X})=\vee_{i=1}^{m} \quad\left(A_{\mathrm{i}} \oplus f\left(X_{\mathrm{i}}\right)\right)=0,
$$

where $\oplus$ stands for the exclusive - OR operation (XOR operation).

Step 2: Use conjunctive elimination (CE) to eliminate $\boldsymbol{X}$ from (2), and obtain the resultant:

$$
\mathrm{CE}(\mathrm{g}(\boldsymbol{A}, \boldsymbol{X}), \boldsymbol{X})=\wedge_{C \in\{0.1\}^{n}} \mathrm{~g}(\boldsymbol{A}, \boldsymbol{C})=0 .
$$


Step 3: Rewrite the switching function in the left-hand side of (3) in a complete-sum (CS) form ${ }^{[3,16,17,19-25]}$

$$
\operatorname{CS}(\operatorname{CE}(\mathrm{g}(\boldsymbol{A}, \boldsymbol{X}), \boldsymbol{X}))=0 \text {. }
$$

The complete sum of a Boolean function $f$, denoted by CS $(f)$, is the all-prime-implicant disjunction that expresses $f$, i.e., it is a sum-ofproducts formula whose terms or products constitute all the prime implicants of $f$ and nothing else. The complete sum is also known as the Blake Canonical Form ${ }^{[3,25]}$. All of the relations implied among the original functions are encoded economically in (4), whose left hand side is a disjunction of all the prime consequents of (1) which do not involve any of the $\boldsymbol{X}$-arguments. Appendix A explains how these prime consequents can be used in tackling the problems referred to in the introduction, deriving maximally independent subsets and minimally dependent subsets of the given set of functions.

\section{VEKM Procedure}

This section adapts the procedure of Section 2 for VEKM implementation using a VEKM with map variables $\boldsymbol{X}$, and entered variables $\boldsymbol{A}$. The VEKM employs a divide-and-conquer strategy for handling the three steps in Section 2, and allows the two steps of conjunctive elimination and complete-sum derivation to run concurrently. Specifically, we note that in equation (4), one can commute the operations of deriving the complete sum (CS) and conjunctive elimination $(\mathrm{CE})^{[7]}$, to obtain:

$\mathrm{CE}(\mathrm{CS}(\mathrm{g}(\boldsymbol{A}, \boldsymbol{X})), \boldsymbol{X})=0$.

However with conventional algebraic or computer manipulation, (5) is more tedious than (4). With VEKM representation, the CE and CS operations can be made to go hand in hand, thereby making (5) more advantageous than (4).

Our procedure utilizes a VEKM technique for complete-sum derivation called VEKM folding, in which a VEKM is used to represent the pertinent function. Entries of the VEKM are converted into completesum entries via algebraic methods employing consensus generation and absorption. Figures 1(a) and 1(b) demonstrate the basic step in VEKM folding which converts a map variable $X_{\mathrm{i}}$ into an entered variable, while retaining CS entries in the new VEKM representation of the pertinent 
function. In Fig. 1(b), we use $\operatorname{ABS}(F)$ to denote an equivalent absorptive formula of $F$, i.e., a formulas obtained from $F$ by successive deletion of terms absorbed in other terms of $F$. The formula in Fig. 1(b) uses ANDing (multiplication) of CS formulas as an alternative for consensus generation. This multiplication is implemented via a multiplication matrix which allows an easy tracking of absorptions because of the fact that if a term is to be ever absorbed, then one of its absorbing terms will belong to either its row or to its column ${ }^{[16]}$. The current procedure adapts VEKM folding, as shown in Fig. 1(c), to produce the CS form of the conjunctive eliminant of the pertinent function, rather than that of the function itself. If the subfunctions $F_{0}$ and $F_{1}$ have some terms in common, i.e., if they can be written as $F_{0}=G_{\text {日 }} H_{0}$, and $F_{1}=G_{\text {日 }} H_{1}$, where $G$ is a disjunction of common terms, then "intelligent multiplication" $^{[3,16]}$ replaces $\operatorname{ABS}\left(F_{0} F_{1}\right)$ in Fig. $1(\mathrm{c})$ by $\operatorname{ABS}\left(G_{0} H_{0} H_{1}\right)$. In a related issue, we note that $\mathrm{CE}(\mathrm{g}(\boldsymbol{A}, \boldsymbol{X}), \boldsymbol{X})$ can be obtained by ANDing the VEKM cells of $\mathrm{g}(\boldsymbol{A}, \boldsymbol{X})$ all at once, but we choose to implement this gradually by eliminating one map variable at a time. This allows the use of multiplication matrices at each step, and hence simplifies the search for potentially absorbable terms.

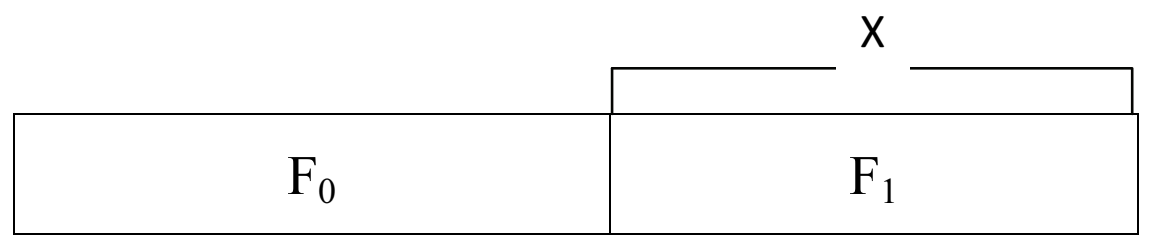

(a) $f(\boldsymbol{X})$ with CS subfunctions $\mathrm{F}_{0}$ and $\mathrm{F}_{1}$

$\operatorname{ABS}\left(\left(\mathrm{F}_{0 \text { 曰 }} X_{\mathrm{i}}\right) \square\left(\mathrm{F}_{1 \text { 曰 }} \bar{X}_{\mathrm{i}}\right)\right)$

(b) $f(\boldsymbol{X})$ in CS form

$\operatorname{ABS}\left(\mathrm{F}_{0} \mathrm{~F}_{1}\right)=\operatorname{ABS}\left(\mathrm{G}_{\text {曰 }} \mathrm{H}_{0} \mathrm{H}_{1}\right)$

(c) $\mathrm{CE}\left\{f(\boldsymbol{X}), X_{\mathrm{i}}\right\}$ in CS form

Fig. 1. The typical step of VEKM folding modified to obtain the conjunctive eliminant of the pertinent function. 
The VEKM version of the Label-and-Elimination procedure can now be stated as follows:

Step 1: Use a VEKM of map variables $\boldsymbol{X}$ and entered variables $\boldsymbol{A}$ to represent $\mathrm{g}(\boldsymbol{A}, \boldsymbol{X})$. Make use of the fact.

$$
A_{i} \oplus f_{i}(\boldsymbol{X})=\left\{\begin{array}{l}
A \text { when } f(\boldsymbol{X})=0 \\
\bar{A} \text { when } f(\boldsymbol{X})-1 .
\end{array}\right.
$$

Equation (6) means that the term $\left(A_{\mathrm{i}} \oplus f_{\mathrm{i}}(X)\right)$ is replaced by $\mathrm{A}_{\mathrm{i}}$ itself in all map cells in which $f_{\mathrm{i}}(\boldsymbol{X})$ is not asserted, and by the complement of $A_{\mathrm{i}}$ in all map cells in which $f_{\mathrm{i}}(\boldsymbol{X})$ is asserted.

Steps 2 and 3 Combined: Make sure that VEKM entries in the VEKM for $\mathrm{g}(\boldsymbol{A}, \boldsymbol{X})$ are represented by CS formulas. If they are not, use a simple algebraic technique, such as the Improved Tison Method ${ }^{[16]}$ to cast them in CS form. Now conjunctively eliminate the map variables of the VEKM, one by one, till a VEKM of 0 map variables and a single cell is obtained. This is precisely a purely-algebraic formula for CE (CS (g $(\boldsymbol{A}, \boldsymbol{X})), \boldsymbol{X})$ or CS $(\mathrm{CE}(\mathrm{g}(\boldsymbol{A}, \boldsymbol{X}), \boldsymbol{X}))$. In each folding, use a multiplication matrix for the conjunction shown in Fig. 1(c), and restrict your application of the ABS(.) operator to comparing a potentially absorbable term to terms in its row and its column.

\subsection{Example 1}

\section{Illustrative Examples}

This example is Example 5.8.1 in p. 139 of Brown $^{[3]}$. It deals with switching (bivalent, two-valued) functions. Table 1 shows the definition of a system of four labeled Boolean functions, its conversion to zeroed equational form, and finally its conversion to a zeroed single-equation of the form $\mathrm{g}(\boldsymbol{A}, \boldsymbol{X})=0$.

Table 1. The problem studied in Example 1 stated in three equivalent forms.

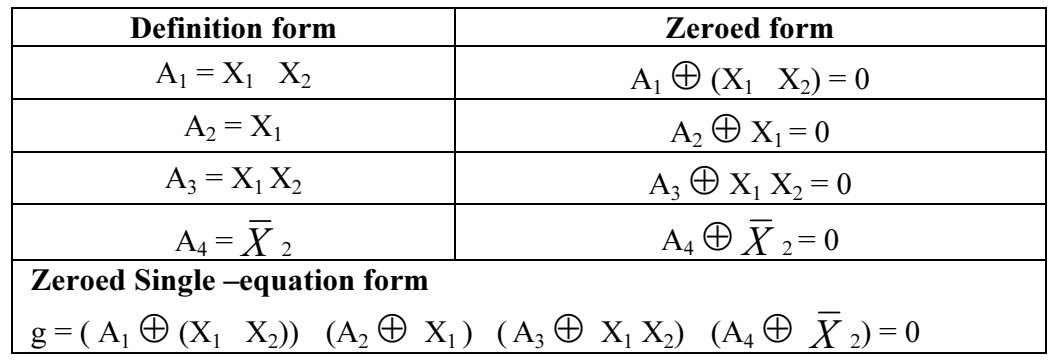


We now represent $\mathrm{g}(\boldsymbol{A}, \boldsymbol{X})$ by a VEKM of map variables $\boldsymbol{X}$ and entered variables $\boldsymbol{A}$. As a first step, Fig. 2 shows the VEKM entries for the specific four terms of $\mathrm{g}(\boldsymbol{A}, \boldsymbol{X})$. According to equation (6), the term $\left(A_{\mathrm{i}} \oplus f_{\mathrm{i}}(\boldsymbol{X})\right)$ is replaced by $\mathrm{A}_{\mathrm{i}}$ itself in all map cells in which $f_{\mathrm{i}}(\boldsymbol{X})$ is not asserted, and by the complement of $A_{\mathrm{i}}$ in all map cells in which $f_{\mathrm{i}}(\boldsymbol{X})$ is asserted. For example, the term $\left(A_{2} \oplus X_{1}\right)$ in $\mathrm{g}(\boldsymbol{A}, \boldsymbol{X})$ contributes the term $A_{2}$ to the entries in the half VEKM of $g$ outside $\mathrm{X}_{1}$ and $\bar{A}_{2}$ to the entries in the half VEKM of $g$ inside $X_{1}$. Figure 3 is a VEKM representing the disjunction of the Four VEKMs in Fig. 2. Each of the entries in Fig. 3 is already in CS form, since each entry is a disjunction of single literals (or also since each variable in any of the entries is monoform, i.e., either complemented or uncomplemented).

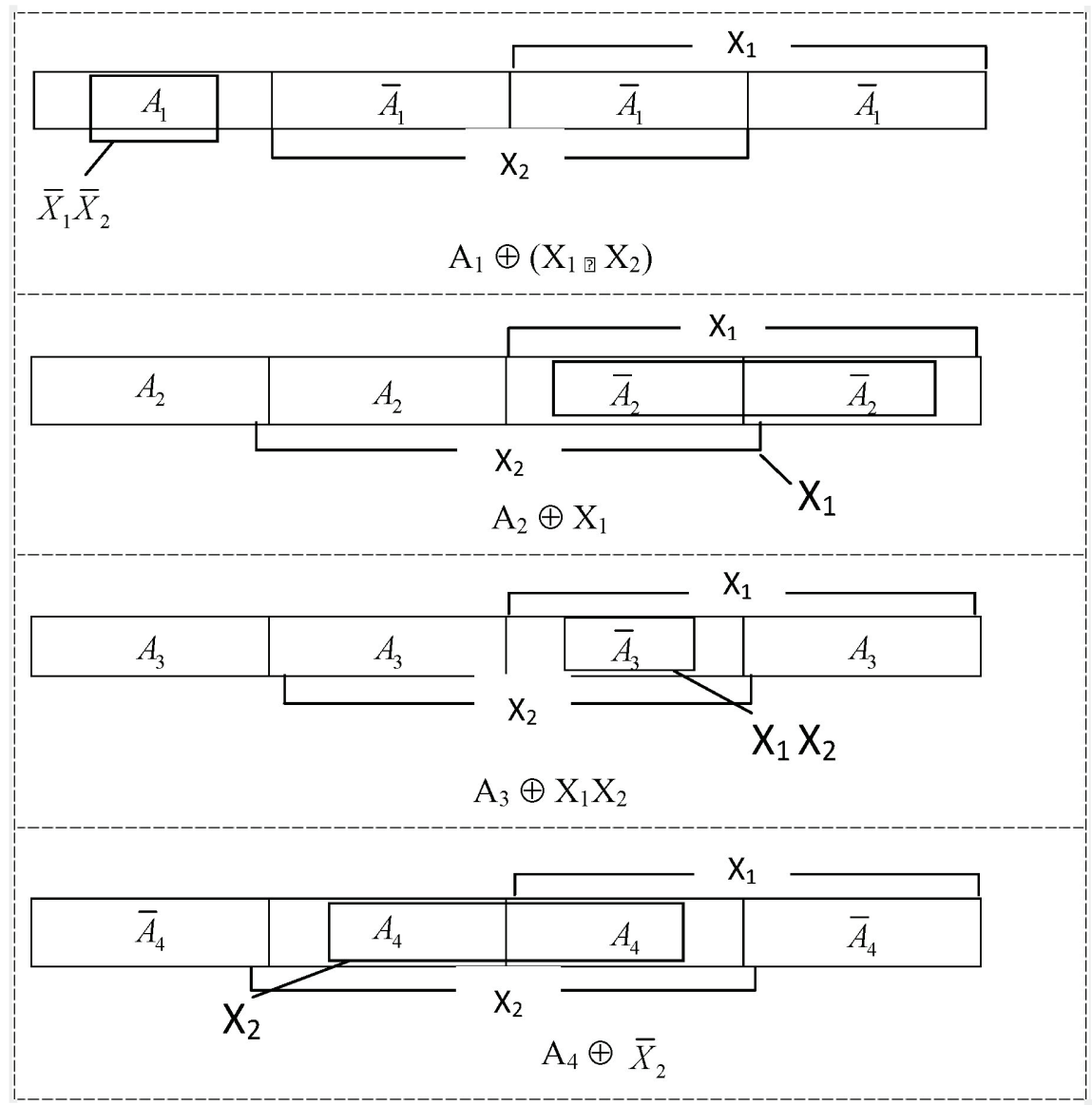

Fig. 2. The VEKM entries for specific terms of $g(\underline{A}, \underline{X})$. 
Now, we perform conjunctive elimination of the two map variables $X_{2}$ and $X_{1}$ one by one as shown in Fig. 4 and 5, respectively. In folding the two $X_{1}$ cells in Fig. 3 into a single cell in Fig. 4, we note that the terms $\bar{A}_{1}$ and $\bar{A}_{2}$ are common to both cells and hence the entry of the unified cell in Fig. 4 is obtained via intelligent multiplication ${ }^{[3,16]}$ as:

$\mathrm{CS}\left(\bar{A}_{1}\right.$ 曰 $\bar{A}_{2}$ 日 $\left(\bar{A}_{3}\right.$ 曰 $\left.\left.A_{4}\right)\left(A_{3 \text { 日 }} \bar{A}_{4}\right)\right)=\bar{A}_{1}$ 曰 $\bar{A}_{2}$ 曰 $\bar{A}_{3} \bar{A}_{4}$ 曰 $A_{3} A_{4}$.

Similarly, the entry in the $\bar{X}_{1}$ cell of Fig. 3 is:

$$
\mathrm{CS}\left(A_{2} \text { 曰 } A_{3} \text { 日 }\left(A_{1} \text { 曰 } \bar{A}_{4}\right)\left(\bar{A}_{1} \text { 曰 } A_{4}\right)\right)=A_{2} \text { 曰 } A_{3} \text { 曰 } \bar{A}_{1} \bar{A}_{4} \text { 曰 } A_{1} A_{4} \text {. }
$$

Figure 5 shows an ANDing Table (Multiplication table) for the two VEKM entries in Fig. 4 to produce CE $(\mathrm{g}(\boldsymbol{A}, \boldsymbol{X}), \boldsymbol{X})$ in CS form. As seen in Fig. 5, absorptions take place within individual rows or within individual columns. The final result is:

$\mathrm{CS}(\mathrm{CE}(\mathrm{g}(\mathrm{A}, \mathbf{X}), \mathbf{X}))=A_{1} \bar{A}_{2} A_{4}$ 曰 $\bar{A}_{2} A_{3}$ 曰 $A_{2} \bar{A}_{3} \bar{A}_{4} \bar{A}_{1} A_{2}$ 曰 $\bar{A}_{1} A_{3}$ 日 $A_{3} A_{4}$ 曰 $\bar{A}_{1} \bar{A}_{4}=0$.

This result has seven A-consequent terms which can be stated in equational form or clausal form as shown in Table 2 . These consequents constitute a complete representation of all the relations holding among the original functions, cast in the simplest form. The set of relations in Table 2 is complete in the sense that any presupposed relation that does not appear in Table 2 must be ruled out, being unsupported by the original premises. For example, Table 2 does not include a relation between $A_{2}=X_{1}$ and $A_{4}=\bar{X}_{2}$ or their complements. This is obvious since these terms involve independent variables.

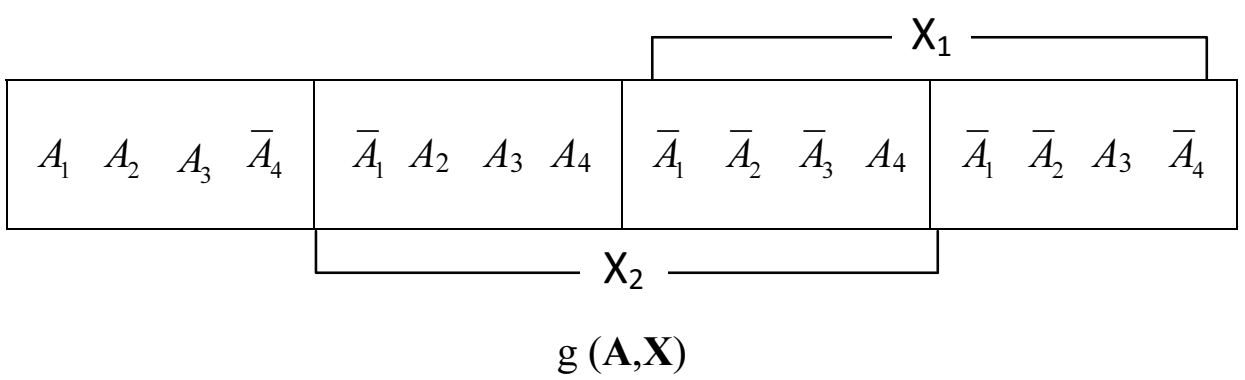

Fig. 3. A CS VEKM representation of the zeroed single-equation of Example 1 with CS entries (Disjunction of VEKMs in Fig. 2). 


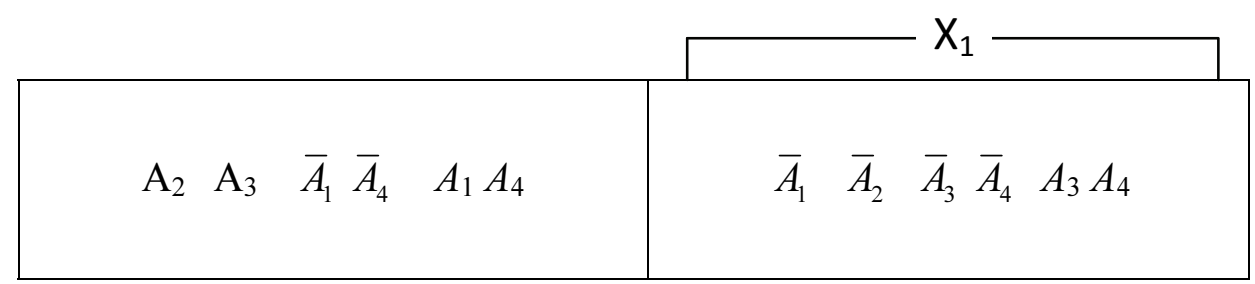

$$
\mathrm{CE}\left(\mathrm{g}(\mathbf{A}, \mathbf{X}),\left\{\mathrm{X}_{2}\right\}\right)
$$

Fig. 4. A CS VEKM representation of the conjunctive eliminant of the function in Fig. 3. w. r. t. $X_{2}$.

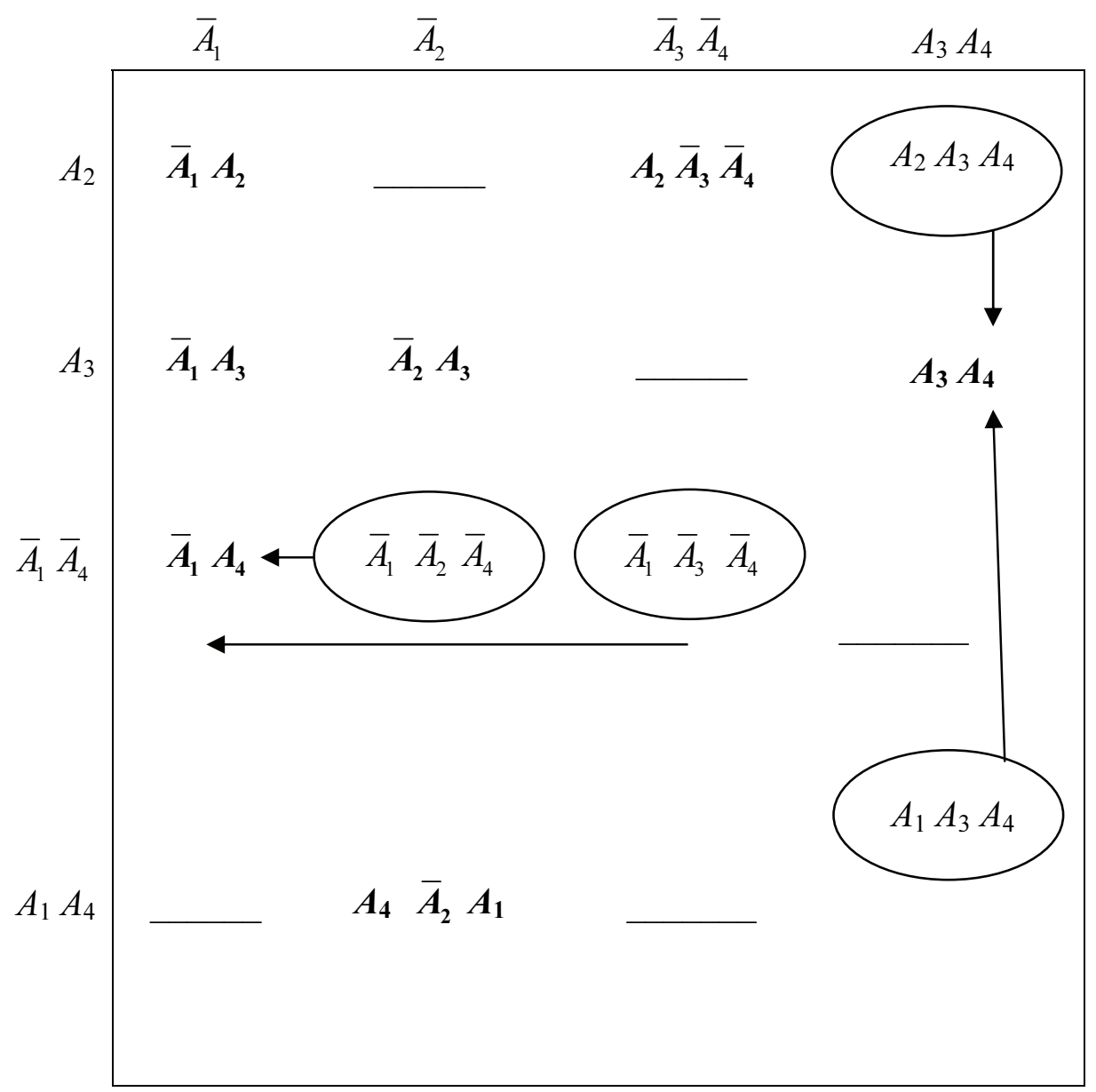

Fig. 5. ANDing table (multiplication table) for the two entries in Fig. 4 to produce $\mathrm{CE}$ $\left(\mathrm{g}(\underline{\mathrm{A}}, \underline{\mathbf{X}}),\left\{\mathrm{X}_{1}, \mathbf{X}_{2}\right\}\right)$ in $\mathrm{CS}$ form. The absorbed terms are encircled and the remaining terms are stressed in bold. 
Table 2. The equational and clausal forms of the A-consequent terms and functional relations.

\begin{tabular}{|c|c|c|c|}
\hline Number & Equational Form & Clausal form & Functional relation \\
\hline $\mathbf{1}$ & $\mathrm{A}_{1} \overline{\mathrm{A}}_{2} \mathrm{~A}_{4}=0$ & $\mathrm{~A}_{1} \mathrm{~A}_{4} \rightarrow \mathrm{A}_{2}$ & $f_{1} f_{4} \leq f_{2}$ \\
\hline $\mathbf{2}$ & $\overline{\mathrm{A}}_{2} \mathrm{~A}_{3}=0$ & $\mathrm{~A}_{3} \rightarrow \mathrm{A}_{2}$ & $f_{3} \leq f_{2}$ \\
\hline $\mathbf{3}$ & $\mathrm{A}_{2} \overline{\mathrm{A}}_{3} \overline{\mathrm{A}}_{4}=0$ & $\mathrm{~A}_{2} \rightarrow \mathrm{A}_{3} \mathrm{~A}_{4}$ & $f_{2} \leq f_{3} f_{4}$ \\
\hline $\mathbf{4}$ & $\overline{\mathrm{A}}_{1} \mathrm{~A}_{2}=0$ & $\mathrm{~A}_{2} \rightarrow \mathrm{A}_{1}$ & $f_{2} \leq f_{1}$ \\
\hline $\mathbf{5}$ & $\overline{\mathrm{A}}_{1} \mathrm{~A}_{3}=0$ & $\mathrm{~A}_{3} \rightarrow \mathrm{A}_{1}$ & $f_{3} \leq f_{1}$ \\
\hline $\mathbf{6}$ & $\mathrm{A}_{3} \mathrm{~A}_{4}=0$ & $\mathrm{~A}_{3} \mathrm{~A}_{4} \rightarrow 0$ & $f_{3} f_{4} \leq 0$ \\
\hline $\mathbf{7}$ & $\overline{\mathrm{A}}_{1} \overline{\mathrm{A}}_{4}=0$ & $1 \rightarrow \mathrm{A}_{1}$ 日 & $1 \leq f_{1} f_{4}$ \\
\hline
\end{tabular}

Table 3. The problem studied in Example 2 stated in three equivalent forms.

\begin{tabular}{|c|c|}
\hline Definition form & Zeroed form \\
\hline $\mathrm{A}_{1}=a \mathrm{X}_{\text {日 }} \mathrm{Y}$ & $\mathrm{A}_{1} \oplus\left(a \mathrm{X}_{\text {回 }} \mathrm{Y}\right)=0$ \\
\hline $\mathrm{A}_{2}=a \mathrm{X}$ & $\mathrm{A}_{2} \oplus a \mathrm{X}=0$ \\
\hline $\mathrm{A}_{3}=\mathrm{X}_{\text {回 }} \bar{a} \mathrm{Z}$ & $\mathrm{A}_{3} \oplus\left(\mathrm{X}_{\text {日 }} \bar{a} \mathrm{Z}\right)=0$ \\
\hline $\mathrm{A}_{4}=Y$ & $\mathrm{~A}_{4} \oplus Y=0$ \\
\hline \multicolumn{2}{|c|}{$\begin{array}{l}\text { Zeroed Single -equation form } \\
\mathrm{g}=\left(\mathrm{A}_{1} \oplus\left(a \mathrm{X}_{\text {日 }} \mathrm{Y}\right)\right)_{\text {日 }}\left(\mathrm{A}_{2} \oplus a \mathrm{X}\right)_{\text {日 }}\left(\mathrm{A}_{3} \oplus\left(\mathrm{X}_{\text {日 }} \bar{a} \mathrm{Z}\right)\right)_{\text {日 }}\left(\mathrm{A}_{4} \oplus Y\right)=0\end{array}$} \\
\hline
\end{tabular}

\begin{tabular}{|c|c|c|c|}
\hline$A_{1 \text { 日 }} A_{2 \text { 日间 }} A_{3 \text { 日 }} A_{4}$ & $\underset{1 \text { 回 } \mathrm{A}_{4} \mathrm{~A}_{2 \text { 回 }} a \mathrm{~A}_{3} \bar{a} \overline{\mathrm{A}}_{3}}{ }$ & $\begin{array}{c}\bar{a} \mathrm{~A}_{1 \text { 回 }} a \overline{\mathrm{A}}_{1 \text { 回 }} \overline{\mathrm{A}_{2}} \text { a } \\
a \overline{\mathrm{A}} 2_{\text {日 }} \overline{\mathrm{A}}_{3 \text { 回 }} \mathrm{A}_{4}\end{array}$ & $\begin{array}{c}\bar{a} \mathrm{~A}_{1 \text { 曰 }} a \overline{\mathrm{A}}_{1 \text { 曰 }} \bar{a} \mathrm{~A}_{2} \text { 日 } \\
a \overline{\mathrm{A}}_{2 \text { 日 }} \overline{\mathrm{A}}_{3 \boxminus} \mathrm{A}_{4}\end{array}$ \\
\hline$\overline{\mathrm{A}}_{1 \text { 日 }} \mathrm{A}_{2 \text { 日 }} \mathrm{A}_{3 \text { 日 }} \overline{\mathrm{A}}_{4}$ & 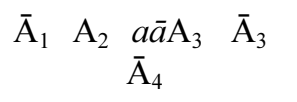 & $\begin{array}{c}\overline{\mathrm{A}}_{1 \text { 日 }} \bar{a} \mathrm{~A}_{\text {日 }} a \overline{\mathrm{A}}_{2 \text { 回 }} \overline{\mathrm{A}}_{3 \text { 回 }} \\
\overline{\mathrm{A}}_{4}\end{array}$ & $\overline{\mathrm{A}}_{1 \text { 曰回 }} \bar{a} \mathrm{~A}_{2 \text { 回 }} \bar{a} \mathrm{~A}_{2 \text { 日 }} \overline{\mathrm{A}}_{3 \text { 日 }}$ \\
\hline
\end{tabular}

$$
\mathrm{g}(\mathbf{A}, \mathrm{X}, \mathrm{Y}, \mathrm{Z})
$$

Fig. 6. A VEKM representation of the zeroed single-equation of Example 2. 


\subsection{Example 2}

This example is Example 5.9.1 in p. 142 of Brown ${ }^{[3]}$. It deals with 'big' Boolean functions $f_{\mathrm{i}}: B^{3}{ }_{4} \rightarrow B_{4}$, where $\mathrm{B}_{4}=\{0, a, \bar{a}, 1\}$ is the Free Boolean algebra $\operatorname{FB}(a)^{[3,18]}$. Table 3 shows the definition of a system of four labeled Boolean functions, its conversion to zeroed equational form, and finally its conversion in to a zeroed single equation of the form $\mathrm{g}(\boldsymbol{A}$, $\boldsymbol{X})=0$. We now represent $\mathrm{g}(\boldsymbol{A}, \boldsymbol{X})$ by a VEKM of map variables $\boldsymbol{X}$ and entered variables $\boldsymbol{A}$. Figure 6 is a VEKM representation (with map variables $X, Y$, and $Z$ ) of the zeroed single function $\mathrm{g}(\boldsymbol{A}, X, Y, Z)$. Most of the entries in this VEKM are already in CS form.

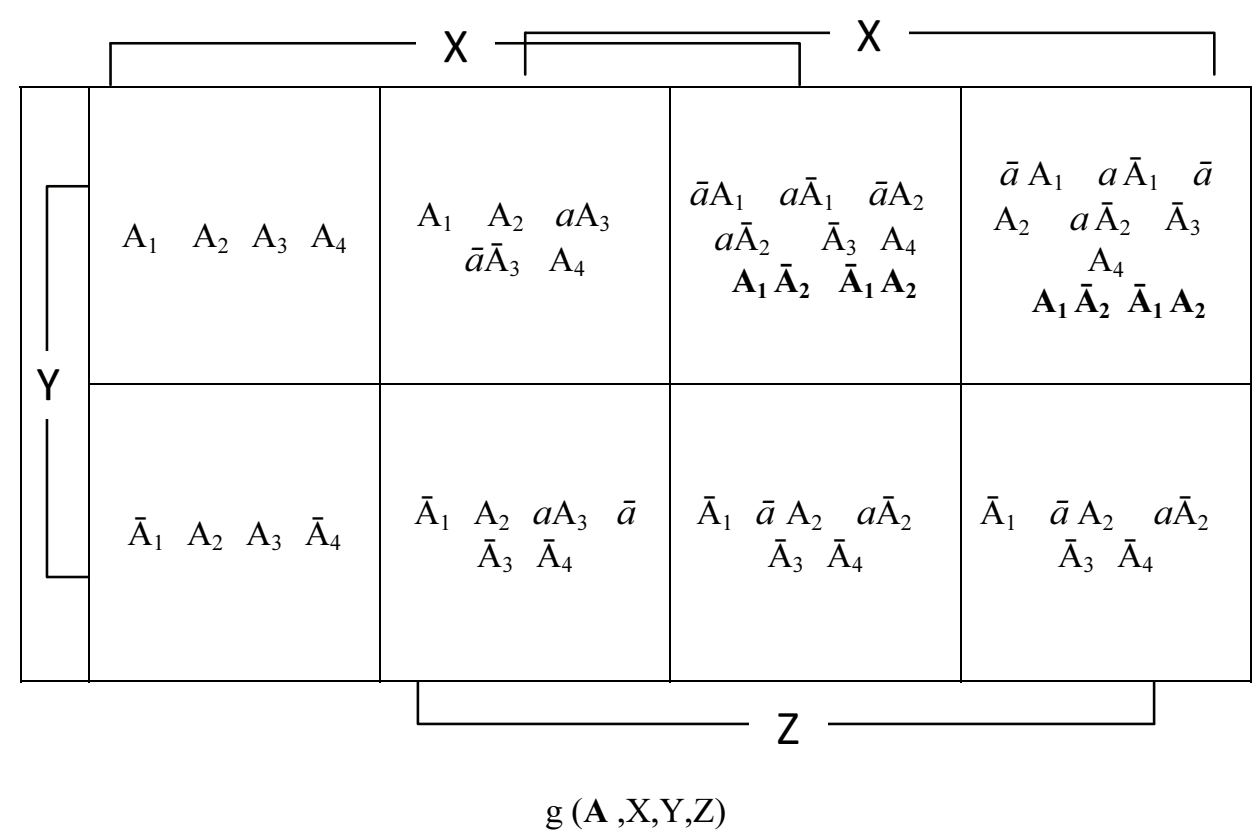

Fig. 7. A VEKM representation of the zeroed single- equation of Example 2 with CS entries. The terms highlighted in bold are consensi added to earlier entries in Fig. 6.

Two exceptions are the two identical entries in the cells $X \bar{Y} Z$ and $X \bar{Y} \bar{Z}$. Each of these two entries is an absorptive formula that has only 3 biform symbols $a, A_{1}$, and $A_{2}$. There are no consensi w. r. t. $A_{1}$ or $A_{2}$. There are two consensi w. r. t. $a$, namely $A_{1} \bar{A}_{2}$ and $\bar{A}_{1} A_{2}$. These two consensi are added to each of the $X \bar{Y} Z$ entry and $X \bar{Y} \bar{Z}$ entry to make it a complete sum, as shown in Fig. 7. Now, we perform conjunctive 
elimination of the three map variables $X, Y$, and $Z$ one by one as shown in Figs. 8, 9, and 10, respectively.

In folding cells of opposing $Z$ values in Fig. 7 into unified cells in Fig. 8, we note that the common entries in the $X \bar{Y} Z$ and $X \bar{Y} \bar{Z}$ in Fig. 7 cells combine into the same entry in cell $X \bar{Y}$ in Fig. 8. Similarly the common entries in the $X Y Z$ and $X Y \bar{Z}$ cells in Fig. 7 combine into the same entry in the $X Y$ cell in Fig. 8. The entries in the $\bar{X} \bar{Y} \bar{Z}$ and $\bar{X} \bar{Y} Z$ cells in Fig. 7 combine into:

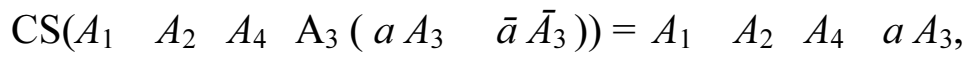

in the cell $\bar{X} \bar{Z}$ of Fig. 8. Similarly, the entries in the $\bar{X} Y \bar{Z}$ and $\bar{X} Y Z$ cells in Fig. 7 combine into:

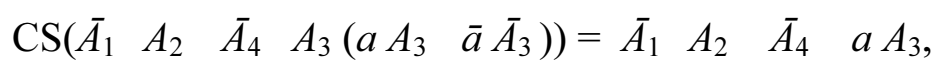

in the cell $\bar{X} Y$ of Fig. 8. Further eliminations of the variable $Y$ in Fig. 9 and variable $Z$ in Fig. 10 are self explanatory. Finally we obtain the disjunction of all consequent terms

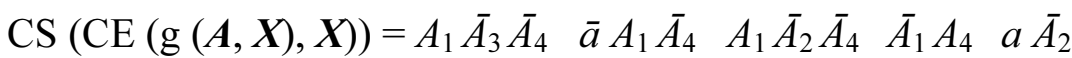

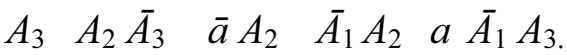

Equation (8) is in agreement with the computer output produced by Brown $^{[3, p .}{ }^{142]}$. Following the procedure in Appendix A, Brown ${ }^{[3]}$ continued to conclude that

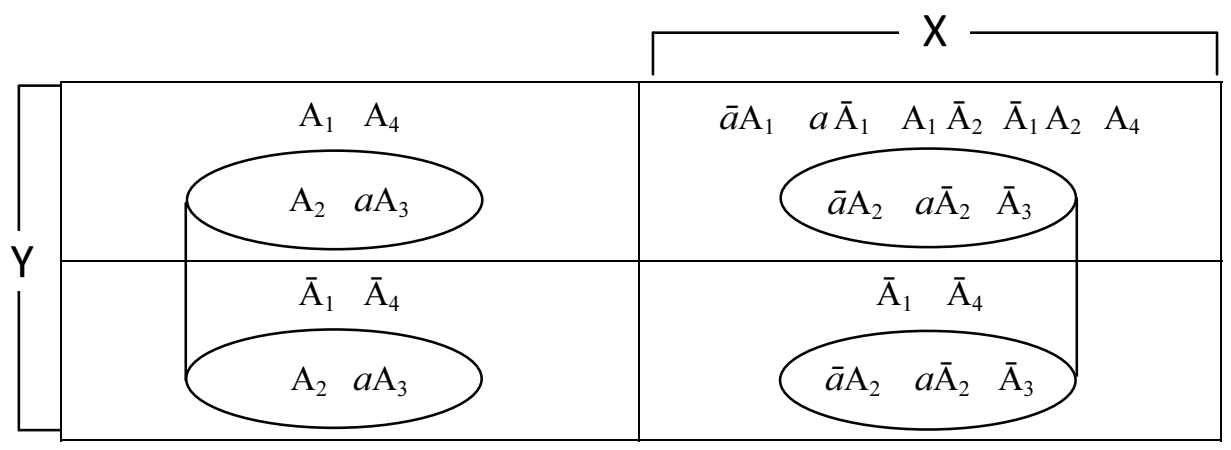

$$
\mathrm{CE}(\mathrm{g}(\mathbf{A}, \mathrm{X}, \mathrm{Y}, \mathrm{Z}),\{\mathrm{Z}\})
$$

Fig. 8. A CS VEKM representation of the conjunctive eliminant of the function in Fig. $7 \mathrm{w}$. r. t. Z. Common terms in the entries of neighboring cells of opposing $Y$ values are encircled (These remain the same upon folding). 


$$
\begin{aligned}
& \mathrm{CS}(W)=A_{1} A_{3 曰} A_{2 \boxminus} A_{1} A_{4}, \\
& \mathrm{CS}(\bar{W})=\bar{A}_{2} \bar{A}_{3} \bar{A}_{4 \text { 日 }} \overline{A_{1}} \overline{A_{2}},
\end{aligned}
$$

and hence showed that the family of minimal dependent subsets is $\left\{\left\{f_{1}, f_{3}\right\},\left\{f_{2}\right\},\left\{f_{1}, f_{4}\right\}\right\}$ and the family of maximal independent subsets is $\left\{\left\{f_{1}\right\},\left\{f_{3}, f_{4}\right\}\right\}$. Figure 11 presents a Hasse diagram (cast in a Karnaugh-map layout ${ }^{[26]}$ ) of all subsets of $\left\{f_{1}, f_{2}, f_{3}, f_{4}\right\}$ designating the 11 dependent sets by blank rectangles and the 5 independent ones by shaded circles. Maximal dependent sets and minimal independent sets are highlighted in bold.

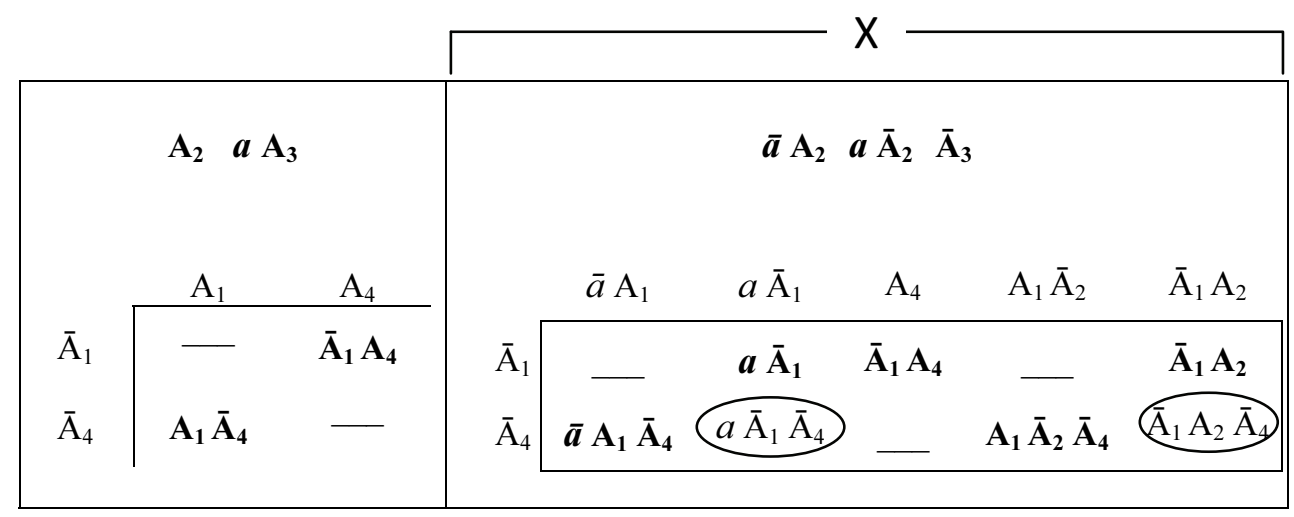

(a) $\mathrm{CE}(\mathrm{g}(\mathbf{A}, \mathrm{X}, \mathrm{Y}, \mathrm{Z}),\{\mathrm{Z}, \mathrm{Y}\})$ in multiplication form

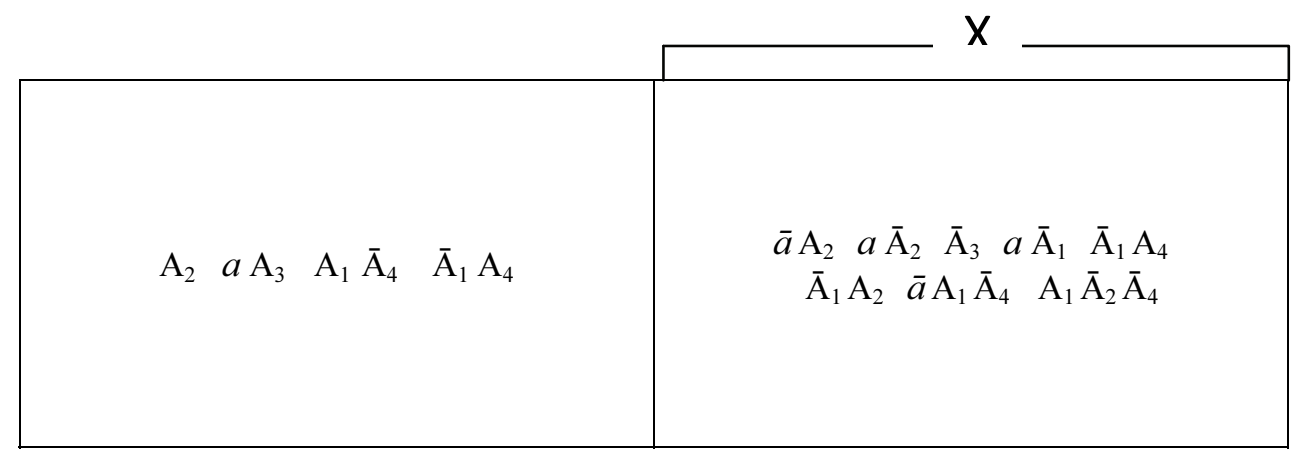

(b) $\mathrm{CE}(\mathrm{g}(\mathbf{A}, \mathrm{X}, \mathrm{Y}, \mathrm{Z}),\{\mathrm{Z}, \mathrm{Y}\})$ in final form

Fig. 9. A CS VEKM representation of the conjunctive eliminant of the function in Fig. 8. w. r. t. $Y$ (or of the function in Fig. 7 w. r. t. $\{Z, Y\})$. 


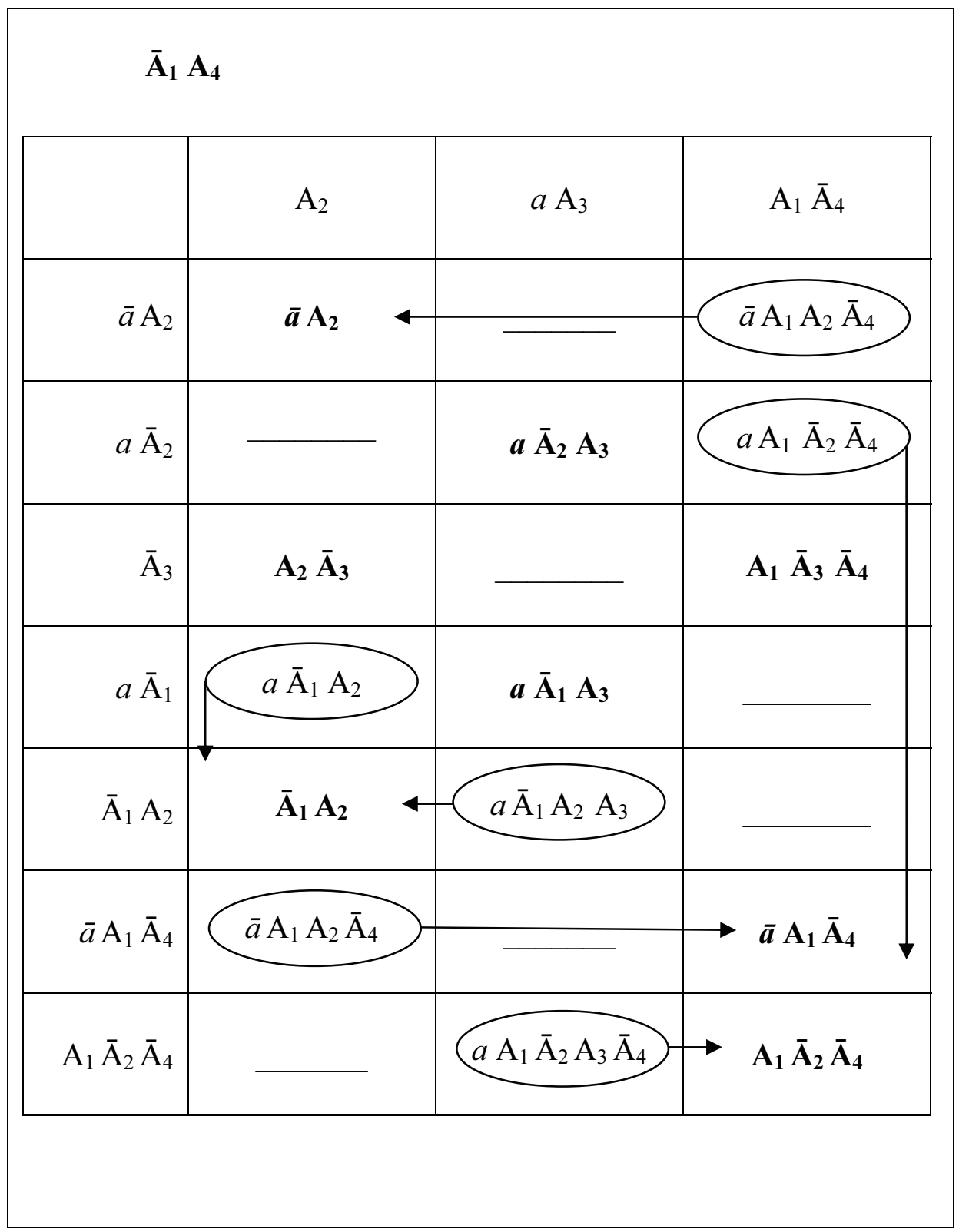

Fig. 10.ANDing table (multiplication table) for the two entries in Fig. 9 to produce CE $(\mathrm{g}(\underline{\mathrm{A}}, \mathbf{X}, \mathbf{Y}, \mathrm{Z}),\{\mathrm{Z}, \mathbf{Y}, \mathbf{X}\})$ in $\mathrm{CS}$ form. The absorbed terms are encircled and the remaining terms are stressed in bold. 


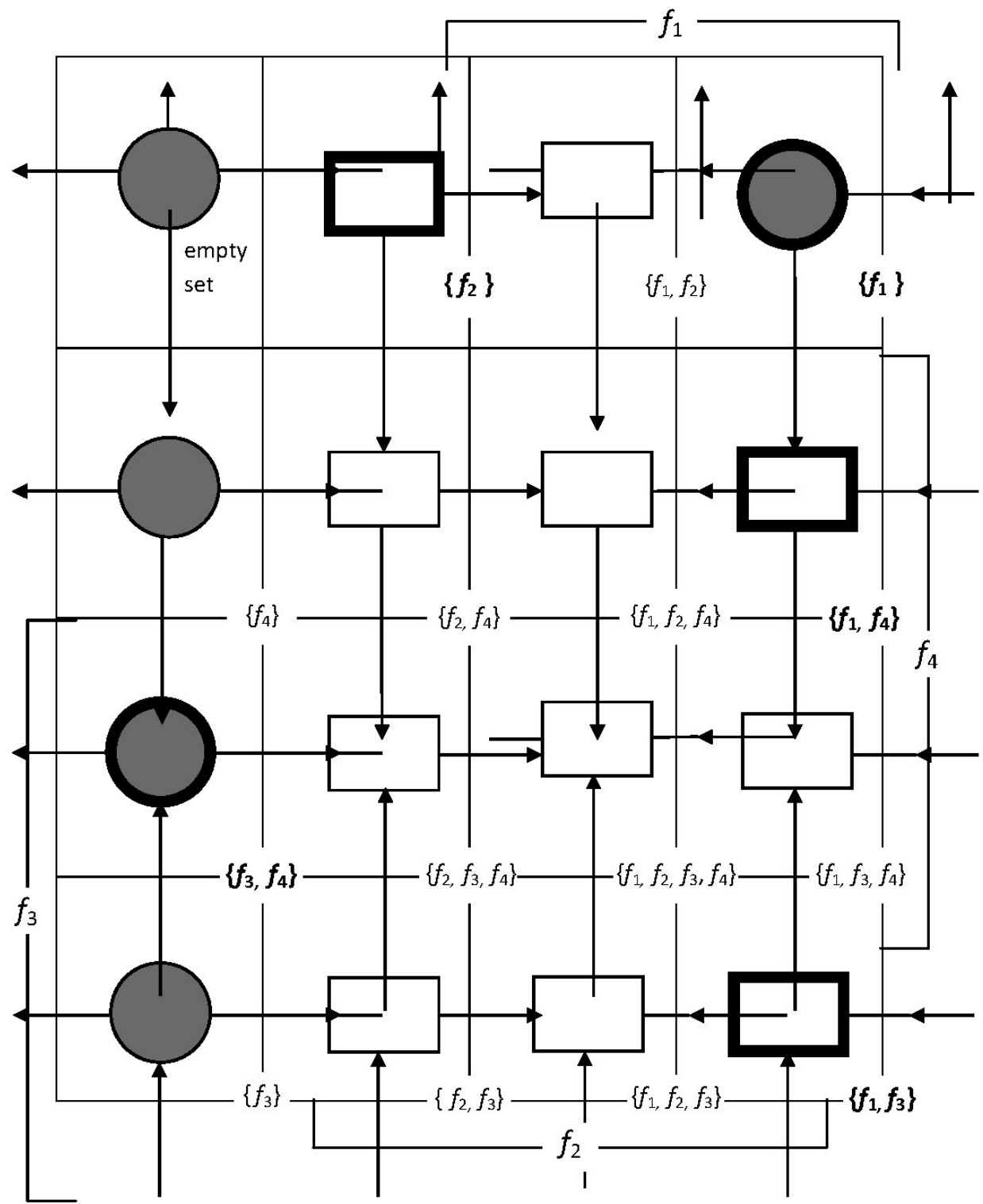

Fig. 11.A Hasse diagram of subsets of $\left\{f_{1}, f_{2}, f_{3}, f_{4}\right\}$ denoting dependent sets by blank rectangles and independent ones by shaded circles. 


\section{Conclusions}

A VEKM perspective was utilized in a tutorial presentation of the concepts and an efficient implementation of the procedures handling Boolean-function dependency. The underlying Boolean algebra could be a simple bivalent switching algebra or a general 'big' Boolean algebra. Several related Boolean-function dependency problems were considered, culminating in the determination of the family of minimal dependent subsets and the complementary family of maximal independent subsets. Not only did the VEKM offer pictorial insight for clarifying the pertinent concepts, but it also acted as a divide-and-conquer strategy for implementing the required procedures. The VEKM proved to be highly suitable for implementing the tasks constituting the basic Label-andEliminate procedure. In particular, the VEKM allowed the combination of the two major tasks of conjunctive elimination and complete-sum derivation. Use of the VEKM resulted in a considerable reduction of the complexity of complete-sum derivation. Consensus generation was restricted to the initial entries of the VEKM, and subsequently avoided through the use of multiplication (ANDing) during VEKM folding. Tracking of absorbable terms was considerably simplified by restricting elimination to one variable at a time, or equivalently by implementing multiplication via a two- dimensional matrix form.

The VEKM technique was demonstrated via two detailed examples. These two examples have been earlier thought to be too complex to be solvable by manual methods. The VEKM technique offered elegant manual solutions to these two examples. Since these solutions are in the canonical complete-sum form, it was straightforward to compare them with computer-produced solutions and to verify that the corresponding sets of solution are identical.

\section{References}

[1] Muller, D.E., Application of Boolean algebra to switching circuit design and to error detection, IRE Transactions on Electronic Computers, EC-3(9): 6-12 (1954).

[2] Ledley, R.S., Digital Computer and Control Engineering. McGraw-Hill, New York, NY, USA (1960).

[3] Brown, F.M., Boolean Reasoning: The Logic of Boolean Equations, Kluwer Academic Puplishers, Boston, USA (1990).

[4] Kuntzmann, J., Alge'bre de Boole. (Algebra of Boole), Dunod, Paris, France (1965). 
[5] Ledley, R.S., Digital computational methods in symbolic logic, with examples in biochemistry, Proceeding of the National Academy of Science, 41(7): 498- 511, (15 July 1955).

[6] Ledley, R.S. and Lusted, L.B., Reasoning foundation of medical diagnosis, Science, 130(3366): 9-21, (3 July 1959).

[7] Rushdi, A.M. and Al-Shehri, A., Selective deduction with the aid of the variable-entered Karnaugh map, Journal of King Abdulaziz University: Engineering Sciences, 15(2): 21-29 (2004).

[8] Thayse, A., Meet and join derivatives and their use in switching theory, IEEE Transactions on Computers, C-27(8): 713-720.

[9] Rushdi, A.M., Symbolic reliability analysis with the aid of variable-entered Karnaugh maps, IEEE Transactions on Reliability, R-32(2): 134-139 (1983).

[10] Rushdi, A.M., Map derivation of the minimal sum of a switching function from that of its complement, Microelectronics and Reliability, 25(6): 1055-1065 (1985).

[11] Rushdi, A.M., Map differentiation of switching functions, Microelectronics and Reliability, 26(5): 891-908 (1986).

[12] Rushdi, A.M., Improved variable-entered Karnaugh map procedures, Computers and Electrical Engineering, 13(1): 41-52 (1987).

[13] Rushdi A.M., Karnaugh map, Encyclopedia of Mathematics, Supplement Volume I: 327328, Hazewinkel, M. (Ed.) Kluwer Academic publishers, Boston, USA (1996). Available at: www.encyclopediaofmath. orge/ index. php/ Karnaugh_map.

[14] Rushdi, A.M. and Al-Yahya, A Boolean minimization procedure using the variable-entered Kamaugh map and the generalized consensus concept, International Journal of Electronics, 87(7): 769-794 (2000).

[15] Rushdi, A.M., Using variable-entered Karnaugh maps to solve Boolean equations, International Journal of Computer Mathematics, 78(1): 23-38 (2001).

[16] Rushdi, A.M. and Al-Yahya, H.A., Derivation of the complete sum of a switching function with the aid of the variable-entered Karnaugh map, King Saud University Journal: Engineering Sciences, 13(2): 239-269 (2001).

[17] Rushdi, A. M., Prime-implicant extraction with the aid of the variable-entered Karnaugh map, Umm Al-Qura University Journal: Science, Medicine and Engineering, 13 (1): 53-74 (2001).

[18] Rushdi, A.M. and Amashah, M.H., Using variable-entered Karnaugh maps to produce compact parametric solutions of Boolean equations, International Journal of Computer Mathematics, 88(15): 3136-3149 (2011).

[19] Blake, A., Canonical Expressions in Boolean Algebra. Ph. D Dissertation, Department of Mathematics, University of Chicago (1937).

[20] Tison, P., Generalization of consensus theory and application to the minimization of Boolean functions, IEEE Transactions on Electronic Computers, EC-16(4): 446-456, (1967).

[21] Reusch, B., Generation of prime implicants from subfunctions and a unifying approach to the covering problem, IEEE Transaction on Computers, C-24(9): 924-930 (1975).

[22] Cutler, R.B., Kinoshita, K. and Muroga, S., Exposition of Tison's Method to Derive all Prime Implicants and all Irredundant Disjunctive Forms for a Given Switching Function. Report No. UIUCDCS-R-79-993. Department of Computer Science, University of Illinois, Urbana, Illinois, USA (1979).

[23] Muroga, S., Logic Design and Switching Theory, Wiley, New York, NY, USA, (1979). 
[24] Brown, F.M. and Rudeanu, S., Prime implicants of dependency functions, Analele Universitatii Bucuresti, 37(2): 16-11 (1988).

[25] Gregg, J.R., Ones and Zeros: Understanding Boolean Algebra, Digital Circuits, and the Logic of Sets, IEEE PRESS, New York, NY, USA (1998).

[26] Rushdi, A.M. and Ba-Rukab, O.M., A brief exposition of a purely-map procedure for twolevel multiple-output logic minimization, International Journal of Computer Mathematics, 84(1): 1-10 (2006).

[27] Brown, F.M. and Rudeanu, S., Consequences, consistency and independence in Boolean algebras, Notre Dame Journal of Formal Logic, 22(1): 45-62 (1981). 


\section{Appendix A: On Dependent Sets of Boolean Functions}

Following Brown ${ }^{[3]}$, we present herein the basic definitions and concepts concerning dependency among Boolean functions. Let $\boldsymbol{B}$ be an arbitrary Boolean algebra, let $T=\left\{f_{1}, f_{2}, \ldots, f_{\mathrm{m}}\right\}$ be a set of Boolean functions mapping $\boldsymbol{B}^{\mathrm{n}}$ into $\boldsymbol{B}$, and let $S=\left\{f_{1}, f_{2}, \ldots, f_{\mathrm{k}}\right\}$ be a subset of $T$ (the first $k$ elements of $T$ are selected, without loss of generality). The subset $S$ is called functionally dependent provided there is a non-constant Boolean function $h: \boldsymbol{B}^{\mathrm{k}} \rightarrow \boldsymbol{B}$ for which the identity

$$
h\left(f_{1}(X), \ldots, f_{\mathrm{k}}(X)\right)=0, \quad\left(\forall \mathrm{X} \in \boldsymbol{B}^{\mathrm{n}}\right),
$$

is fulfilled; otherwise $\mathrm{S}$ is called functionally independent.

Every subset of an independent set is independent; in particular, the empty set is independent. Every superset of a dependent set is also dependent; but the set of dependent subsets might be empty. An independent set is maximal in case there is no independent set strictly including it; a dependent set is minimal in case there is no dependent set strictly included in it.

To derive the maximal independent and minimal dependent subsets of $T$, we construct a complement-free SOP formula W from (4) as follows. If CS(CE $(\mathrm{g}(\boldsymbol{A}, \boldsymbol{X}), \boldsymbol{X}))$ is null, then $\mathrm{W}$ is defined to be null; otherwise, the terms of $\mathrm{W}$ are formed in one-to-one correspondence with the terms of $\operatorname{CS}(\operatorname{CE}(\mathrm{g}(\boldsymbol{A}, \boldsymbol{X})$, $\boldsymbol{X})$ ) by:

(i) deleting all constants (elements of $\boldsymbol{B}$ ), and

(ii) replacing either $A_{\mathrm{i}}$ or $\overline{A_{\mathrm{i}}}$ by $A_{\mathrm{i}}(i=1,2, \ldots, m)$.

The formula $W$ represents the dependency function associated with the system. The set $S=\left\{f_{1}, f_{2}, \ldots, f_{\mathrm{k}}\right\}$ is a minimal dependent subset of $T$ if and only if $A_{1} \ldots$ $A_{\mathrm{k}}$ is a term of CS $(W)$. Likewise, the set complement of $S$ relative to $T$, namely $\bar{S}=T-S=\left\{f_{\mathrm{k}+1}, \ldots, f_{\mathrm{m}}\right\}$ is a maximal independent subset of $T$ if and only if $\overline{A_{1}} \ldots \overline{A_{\mathrm{k}}}$ is term of $\mathrm{CS}(\bar{W})^{[3,27]}$. 


\section{Appendix B: The Variable-Entered Karnaugh Map}

The construction of a variable-entered Karnaugh map is based on the Boole-Shannon expansion of Boolean functions ${ }^{[3,12,15,18]}$. If $f: \boldsymbol{B}^{\mathbf{n}} \rightarrow \boldsymbol{B}$, is a Boolean function of $n$ variables, then it can be expanded about $m$ of its $n$ variables, $0 \leq m \leq n$, as follows. Let $\boldsymbol{X}_{\mathrm{p}}, \boldsymbol{X}_{\mathrm{e}}, \boldsymbol{X}$ denote respectively the m-tuple, the $(n-m)$-tuple and the $n$-tuple

$$
\begin{aligned}
& \boldsymbol{X}_{\mathrm{p}}=\left[X_{1}, X_{2}, \ldots, X_{\mathrm{m}}\right], \\
& \boldsymbol{X}_{\mathrm{e}}=\left[X_{\mathrm{m}+1}, X_{\mathrm{m}+2}, \ldots, X_{\mathrm{n}}\right], \\
& \boldsymbol{X}=\left[\boldsymbol{X}_{\mathrm{p}}, \boldsymbol{X}_{\mathrm{e}}\right],
\end{aligned}
$$

then $f(\boldsymbol{X})=f\left(\boldsymbol{X}_{\mathrm{p}}, \boldsymbol{X}_{\mathrm{e}}\right)$ can be written in the form

$$
\begin{aligned}
& f\left(X_{1}, X_{2}, \ldots, X_{\mathrm{m}-1}, X_{\mathrm{m}}, X_{\mathrm{e}}\right)=\bar{X}_{1} \bar{X}_{2} \ldots \bar{X}_{\mathrm{m}-1} \bar{X}_{\mathrm{m}} f_{0} \text { 曰 } \bar{X}_{1} \bar{X}_{2} \ldots \\
& \bar{X}_{\mathrm{m}-1} X_{\mathrm{m}} f_{1 \text { 曰ํ日 }} X_{1} X_{2} \ldots X_{\mathrm{m}-1} X_{\mathrm{m}} f_{(2}^{\mathrm{m}-1)},
\end{aligned}
$$

where

$$
\begin{aligned}
& f_{0=} f\left(0,0, \ldots, 0,0, \boldsymbol{X}_{\mathrm{e}}\right)=f(\boldsymbol{X}) / \bar{X}_{1} \bar{X}_{2} \ldots \bar{X}_{\mathrm{m}-1} \bar{X}_{\mathrm{m}}, \\
& f_{l=} f\left(0,0, \ldots, 0,1, \boldsymbol{X}_{\mathrm{e}}\right)=f(\boldsymbol{X}) / \bar{X}_{1} \bar{X}_{2} \ldots \bar{X}_{\mathrm{m}-1} \bar{X}_{\mathrm{m}}, \\
& \left.f_{(2}{ }^{m}-1\right)=f\left(1,1, \ldots, 1,1, \boldsymbol{X}_{\mathrm{e}}\right)=f(\boldsymbol{X}) / X_{1} X_{2} \ldots X_{\mathrm{m}-1} X_{\mathrm{m}},
\end{aligned}
$$

are called subfunctions, restrictions, residuals or ratios of the original function $f(\boldsymbol{X})$. Each of them is obtained from $f(\boldsymbol{X})$ through certain assignments or specifications to its $m$ expansion variables. Therefore, each subfunction is a function of the remaining $(n-m)$ variables $\boldsymbol{X}_{\mathbf{e}}$ only, though not necessarily a genuine function of all of them. The expansion (B.4) can be used to represent $f(\mathbf{X})$ in terms of a map of m map variables namely $X_{1}, X_{2}, \ldots, X_{\mathrm{m}}$. Such a map is called a variable-entered Karnaugh map (VEKM) since the entries of its $2^{\mathrm{n}}$ cells are formulas representing the (generally) n-variable subfunctions $f_{o}, f_{l} \ldots, f_{(2 \mathrm{~m}-1)}$. Actually, if the product $X_{\mathrm{I}} X_{2} \ldots X_{\mathrm{m}-1} X_{\mathrm{m}}$ is of a value equal to the binary representation for the integer $\mathrm{i}$, then the entry of the corresponding map cell is $f_{i}$. When the expansion (B.4) is associated with a VEKM representation, the $m$ expansion variables $\boldsymbol{X}_{p}$ are called keystone or map variables while the $e=(m-n)$ remaining variables are called entered variables.

Without loss of generality, the variables $X_{1}, X_{2}, \ldots, X_{\mathrm{n}}$ of the function $f$ are assumed to be arranged such that the first $m$ among them are map variables. For a given number $\mathrm{m}$ where $0 \leq m \leq n$, there is ${ }^{\mathrm{n}} C_{\mathrm{m}}$ possible choices for the set of map variables. Therefore, there are ${ }^{\mathrm{n}} C_{\mathrm{m}}$ types of expansions or VEKM 
representations for the Boolean function $f(X)$. The total number of such VEKM representations is:

$$
N=\sum_{m=0}^{n}\left({ }^{\mathrm{n}} C_{m}\right)=2^{\mathrm{n}} .
$$

Note that a VEKM representation is unique only as far as the choice of its map and entered variables is concerned, but there are usually many possible formulas for its subfunctions. Out of the $2^{\mathrm{n}}$ VEKM representations, the two extreme ones are not genuine VEKMs. For $m=0$ and $e=n$, a VEKM degenerates into a purely-algebraic expression, while for $m=n$, and $e=0$, a VEKM degenerates into a conventional or classical Karnaugh map (CKM), i.e., to a map of constant rather than variable entries. However, the point of view that these two extreme cases belong to our coterie of VEKMs is indeed very useful. Rushdi ${ }^{[12]}$ discusses ways of transformations among various VEKM representations. If the number of map variables is to be increased from $\mathrm{m}$ to $k>$ $m$ say, then each of the $2^{\mathrm{m}}$ subfunctions of the original VEKM is expanded about the new $(k-m)$ map variables according to (B.4) to yield $2^{(k-m)}$ subfunctions of its own, with a number of $2^{k}$ subfunctions emerging for the new VEKM. On the other hand, if the number of map variables is to be decreased from $k$ to $m$, then the original VEKM is divided into $2^{\mathrm{m}}$ disjoint partitions each of which consists of $2^{(k-m)}$ of the original VEKM cells which have common values for the $(k-m)$ original map variables that are to be eliminated as map variables and switched into entered variables. These partitions are VEKM representations for the subfunctions of the new VEKM and hence can be used to produce algebraic expressions for them.

The VEKM has been originally developed to double the variable handling capability of the CKM while retaining most of its pictorial insight ${ }^{[12]}$. Later, other merits of the VEKM have been revealed. In particular, the VEKM was shown to be the natural map for representing 'big' Boolean algebras ${ }^{[3,15,18]}$, and hence served for insightful handling of a variety of problems dealing with these $\operatorname{algebras}^{[15,18]}$. 


\section{استخدام خر ائط كارنوه متغيرة المحتويات في تحديد}

المجمو عات المعتمدة و المجمو عات المستقلة للدو ال البو لانية

\section{علي محمد علي رشدي، و حسين مبارك البركاتي}

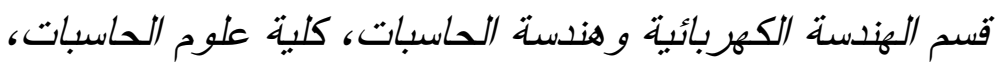

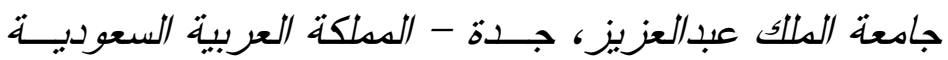

\section{arushdi@kau.edu.sa}

الدستخلص. إن إحدى الطو ائف المهمة لمسائل الاستخلال المنطقـي صني

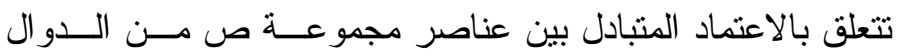

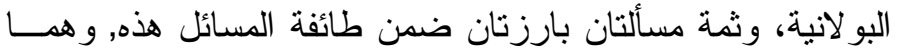

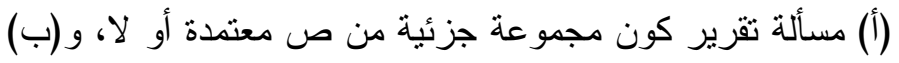

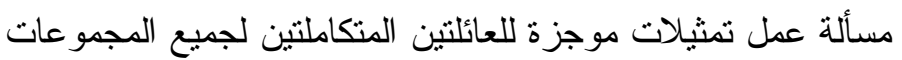

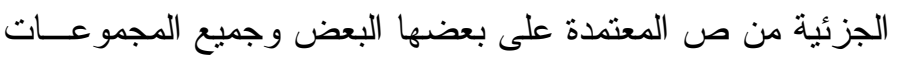

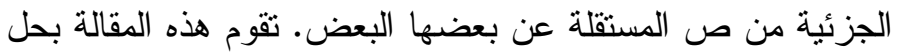

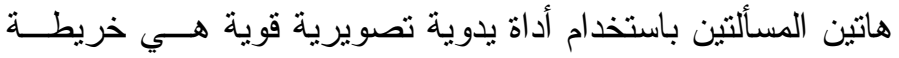

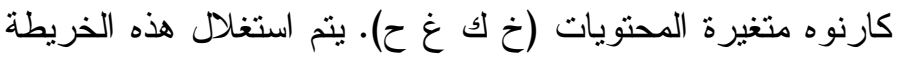

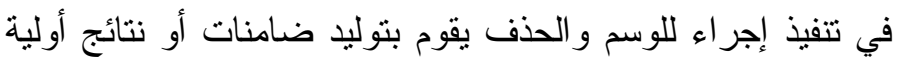

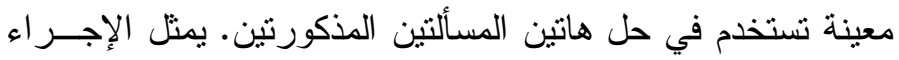

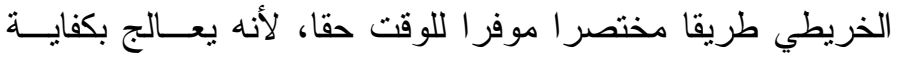

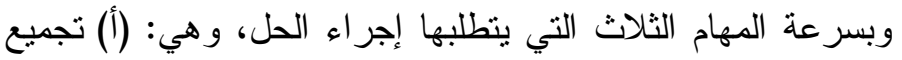

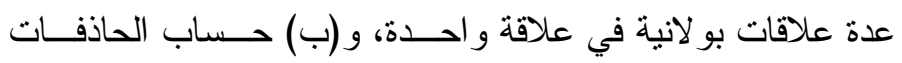

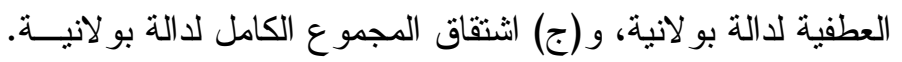

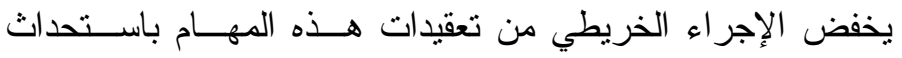

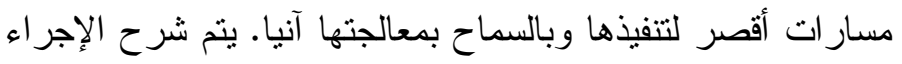

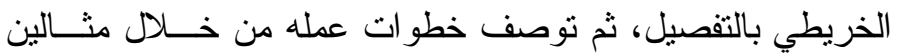

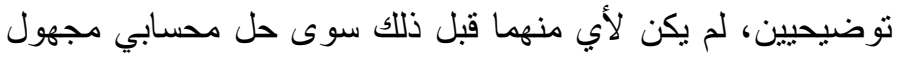

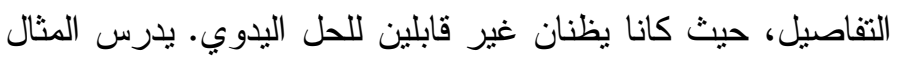


الأول دو ال تبديلية ثنائية القيمة، بينما يتتاول المثتـال التـاني دو الاً

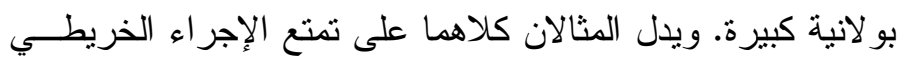
المقدم هنا بمز ايا التبصرية و البساطة و الكفاية أو السرعة الإندة.

الكلمات الدالة: المجموعات الجزئية المستقلة الأعظمية، المجموعات

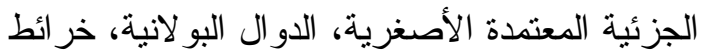

كارنوه متغيرة المحتويات. 